\title{
The prevalence of alcohol and illicit drug use among injured patients presenting to the emergency department of a national hospital in Tanzania: a prospective cohort study
}

Müller M. Mundenga ${ }^{1,2^{*}}$, Hendry R. Sawe ${ }^{1,3}$, Michael S. Runyon ${ }^{4}$, Victor G. Mwafongo ${ }^{1}$, Juma A. Mfinanga ${ }^{3}$ and Brittany L. Murray ${ }^{1,5}$

\begin{abstract}
Background: Alcohol and illicit drugs have been found to be major contributing factors leading to severe injuries in a variety of settings. In Tanzania, the use of these substances among injured patients has not been studied. We investigated the prevalence of positive tests for alcohol and illicit drug use among injured patients presenting to the emergency medicine department (ED) of Muhimbili National Hospital (MNH).

Methods: This was a prospective cohort study of a consecutive sample of patients $>18$ years of age presenting to the ED-MNH with injury related complaints in October and November 2015. A structured data sheet was used to record demographic information, mechanism of injury, clinical presentation, alcohol and illicit drug test results, and ED disposition. Alcohol levels and illicit drug use were tested by breathalyser device or swab stick alcohol test and multidrug urine panel, respectively. Patients were followed up for $24 \mathrm{~h}$ and 30 days using medical chart reviews and phone calls. Descriptive statistics and relative risk were used to describe the results.
\end{abstract}

Results: We screened 1011 patients and we enrolled all 143 (14.1\%) patients who met inclusion criteria. 123 (86.0\%) were male, the median age was 30 years (IQR: 23-36 years). The most frequent mechanism of injury was road traffic accidents (84.6\%). 67/143 (46.9\%) patients tested positive for alcohol and 44/122 (36.1\%) patients tested positive for drugs. $29(26.1 \%)$ tested positive for alcohol and drugs. The most frequently detected illicit drug was marijuana in 30/122 (24.5\%) injured patients. 23/53 (43.4\%) patients with positive alcohol testing self-reported alcohol use. 3/25 patients with positive illicit drug tests who were able to provide self-reports, self-reported drug use. At 30-day followup, 43 (64.2\%) injured patients who tested positive for alcohol had undergone major surgery, 6 (9.0\%) had died, and 36 (53.7\%) had not yet returned to their baseline.

Conclusions: The prevalence of alcohol and illicit drugs is very high in patients presenting to the ED-MNH with injury. Further studies are needed to generalise the results in Tanzania. Public health initiatives to decrease drinking and/or illicit drug use and driving should be implemented.

Keywords: Alcohol, Illicit drugs, Injured patients, Road traffic injury, Emergency medicine

\footnotetext{
* Correspondence: mundenga2013@gmail.com

${ }^{1}$ Department of Emergency Medicine, Muhimbili University of Health and

Allied Sciences, Dar es Salaam, Tanzania

${ }^{2}$ Heal Africa Hospital, Goma, Democratic Republic of Congo

Full list of author information is available at the end of the article
}

(c) The Author(s). 2019 Open Access This article is distributed under the terms of the Creative Commons Attribution 4.0 International License (http://creativecommons.org/licenses/by/4.0/), which permits unrestricted use, distribution, and reproduction in any medium, provided you give appropriate credit to the original author(s) and the source, provide a link to the Creative Commons license, and indicate if changes were made. The Creative Commons Public Domain Dedication waiver (http://creativecommons.org/publicdomain/zero/1.0/) applies to the data made available in this article, unless otherwise stated. 


\section{Background}

In high-income countries (HIC), hospital-based emergency department (ED) studies have demonstrated a clear link between alcohol and illicit drug use and the occurrence of injuries, as well as injury-related deaths [1]. In low- and middle-income countries (LMIC) little is known about alcohol and drug use among injured patients even though the World Health Organization (WHO) estimates that $90 \%$ of injury-related deaths worldwide occur in LMIC [2, 3]. The few studies that have been done in sub-Saharan Africa to illustrate the prevalence of alcohol and illicit drug use among injured patients show that alcohol is the most commonly described substance [4-6].

Although many studies conducted in both HIC and LMIC have used patient report to screen for alcohol and illicit drug use in injured patients, analytical testing has been shown to be more accurate, specifies the substances used, allows this testing in patients with altered mental status, and avoids underestimation of alcohol and drug use [7-9].

In Africa, the majority of studies on substance use in injured patients rely on patient report of alcohol and illicit drug use, with the exception of few studies conducted in the Ivory Coast, Ghana, and South Africa which used objective testing [10-12]. In Tanzania, most studies examining alcohol and illicit drug use have been done in non-injured patients $[13,14]$. Unfortunately, none of those studies have used objective testing to screen for alcohol and illicit drugs use, and none of them focused on injured patients presenting to an ED of a tertiary level facility. As severely injured patients are referred to tertiary level facilities in Tanzania, this is an important distinction.

The aim of this study was to determine the prevalence of injured patients with a positive test for alcohol and/or illicit drug use, to characterize the various substances of abuse found, to compare the patient report of substance abuse with the results of analytic testing, and to determine the 24-h and 30-day morbidity and mortality rates of injured patients with positive tests for alcohol and/or illicit drugs. This information will provide an improved understanding of the scope of this problem in Tanzania and will help to guide future research and public health intervention strategies that may benefit patients in our region.

\section{Methods}

\section{Study design}

This is a prospective descriptive cohort study of a consecutive sample of 143 patients aged 18 years and above presenting to the ED-MHH, Dar es Salaam, Tanzania within $12 \mathrm{~h}$ of sustaining an injury between 17th October 2015 and 4th November 2015.

\section{Study setting and population}

This study was conducted at the Emergency Department of Muhimbili National Hospital (ED-MNH). MNH is the national hospital of Tanzania. It is located in Ilala district, Dar es Salaam, Tanzania. MNH has a capacity of 1500 beds. $\mathrm{MNH}$ is the highest level of medical care available in the government system in Tanzania, and thus severely injured patients from across the country are referred to $\mathrm{MNH}$. When arriving at $\mathrm{MNH}$, these patients are first evaluated in the ED-MNH. The ED-MNH is open $24 \mathrm{~h}$ every day and sees an average of 60,000 patients per year, including approximately 1500 trauma patients per month. It has 3 adult resuscitation rooms and one paediatric resuscitation room. The ED was built in 2009 and opened to patients in January 2010; it is the only recognized public ED in Tanzania. The staff of the ED-MNH is composed of emergency medicine trained faculty, residents, registrars, interns, and nurses. It is a teaching department with a formal residency program which was started in 2010 [15]. Drug and alcohol testing is currently not routinely available at government hospitals in Tanzania. This testing is only performed in special toxicological or suspicious legal cases by the chief chemist of the Government. Our study population included all injured patients aged 18 years and above who arrived at the ED-MNH within $12 \mathrm{~h}$ of their injury.

\section{Study protocol}

Patient testing and enrollment was completed by the principal investigator and a trained research assistant. All patients arriving at the ED-MNH were screened for eligibility. For patients who met inclusion criteria, we obtained written informed consent. This consent was obtained from the patient if they had capacity, or from the appropriate proxy/relative if the patient had altered mental status. A structured data collection form was used to record age, sex, location of the injury, mechanism of the injury, severity of the injury, patient and relative report of alcohol and illicit drug use, and nurse, and physician presumption of alcohol and drug use.

Blood alcohol concentration was measured by using a Breathalyzer (BACtrack Select S80 Breathalyzer) for those able to properly use the breathalyser. For patients unable to properly use the breathalyser, saliva swab sticks (Instant Alcohol Saliva Test Strips/W53-S) were used to measure the level of alcohol. TheRapidCHECK 5 Multi-Drug Panel Test, was used to identify illicit drugs using urine samples. It screened for the presence of opioids, cocaine, marijuana, amphetamines, and benzodiazepines.

\section{Key outcome measures}

The primary outcomes were: 1) the prevalence of injured patients with a positive test for alcohol/ illicit drugs at the time of presentation to the ED-MNH; 2) the characteristics of the various substances of abuse among injured patients with a positive test for alcohol and/or illicit drug use at the time of presentation to the ED-MNH; 3) the comparison 
of patient report, relative report and healthcare provider suspicion of alcohol and/or illicit drug use with the results of objective testing for alcohol and illicit drug use among injured patients presenting to the ED-MNH.

The secondary outcomes were 24-h and 30-day morbidity and mortality rates of injured patients with a positive test for alcohol and/or illicit drugs presenting to the ED-MNH.

All patients were followed up for 30 days and admission to the hospital, need for surgery, 24-h mortality, 30-day mortality, and 30-day return to baseline were recorded.

\section{Data analysis}

Data was collected on hand-written data collection forms and then entered into Microsoft Excel (Microsoft Corporation, Redmond, WA) and analysed with Microsoft Excel. Data was summarized in tables using descriptive statistics, percentages, inter quartile ranges, sensitivity and specificity, positive and negative predictive value, relative risk, and $95 \%$ confidence intervals were used as appropriate.

\section{Results}

\section{Study population demographics}

During the study period, a total of 1011 adult patients were attended at the ED-MNH, of which 202 had trauma related complaints. Out of 202 patients with trauma, $143(70.8 \%)$ met the inclusion criteria for the study (Fig. 1). All 143 eligible patients were enrolled. $86.0 \%(n=123)$ of patients were male, and their median age was 30 years (IQR 23-36). All 143 patients enrolled were tested for alcohol. Because we were unable to obtain urine from 21 patients during their time in the ED, we tested only 122/143 (85.3\%) patients for illicit drugs. 121 (84.6\%) of patients were injured on the road, followed by $14(9.8 \%)$ at home, and other locations $(5.6 \%)$ as shown in Table 1. $80.4 \%(n=115)$ of patients were referred from peripheral health centers, $10.4 \%(n=$ 15) were self-referred, and $9.1 \%(n=13)$ were brought by the police (Table 1).

\section{Results of alcohol and illicit drug testing among injured patients}

67 (46.9, 95\% CI: 39.3-54.7\%) patients tested positive for alcohol. Among the 122 patients who were tested for illicit drugs, 44 (36.0, 95\% CI: 27.2-44.8\%) tested positive. Out of the 122 injured patients who were tested for both alcohol and illicit drugs, 29 (23.7, 95\% CI: 16.5-32.3\%) tested positive for both alcohol and illicit drugs, 46 (37.7, 95\% CI: 29.1-46.9\%) tested negative for both alcohol and illicit drugs, and 82 (57.3, 95\% CI: 49.2 to $69.1 \%$ ) patients tested positive for either alcohol or illicit drugs. (Table 2)

Among the 67 patients who tested positive for alcohol, 42 (62.7\%) had blood alcohol concentrations

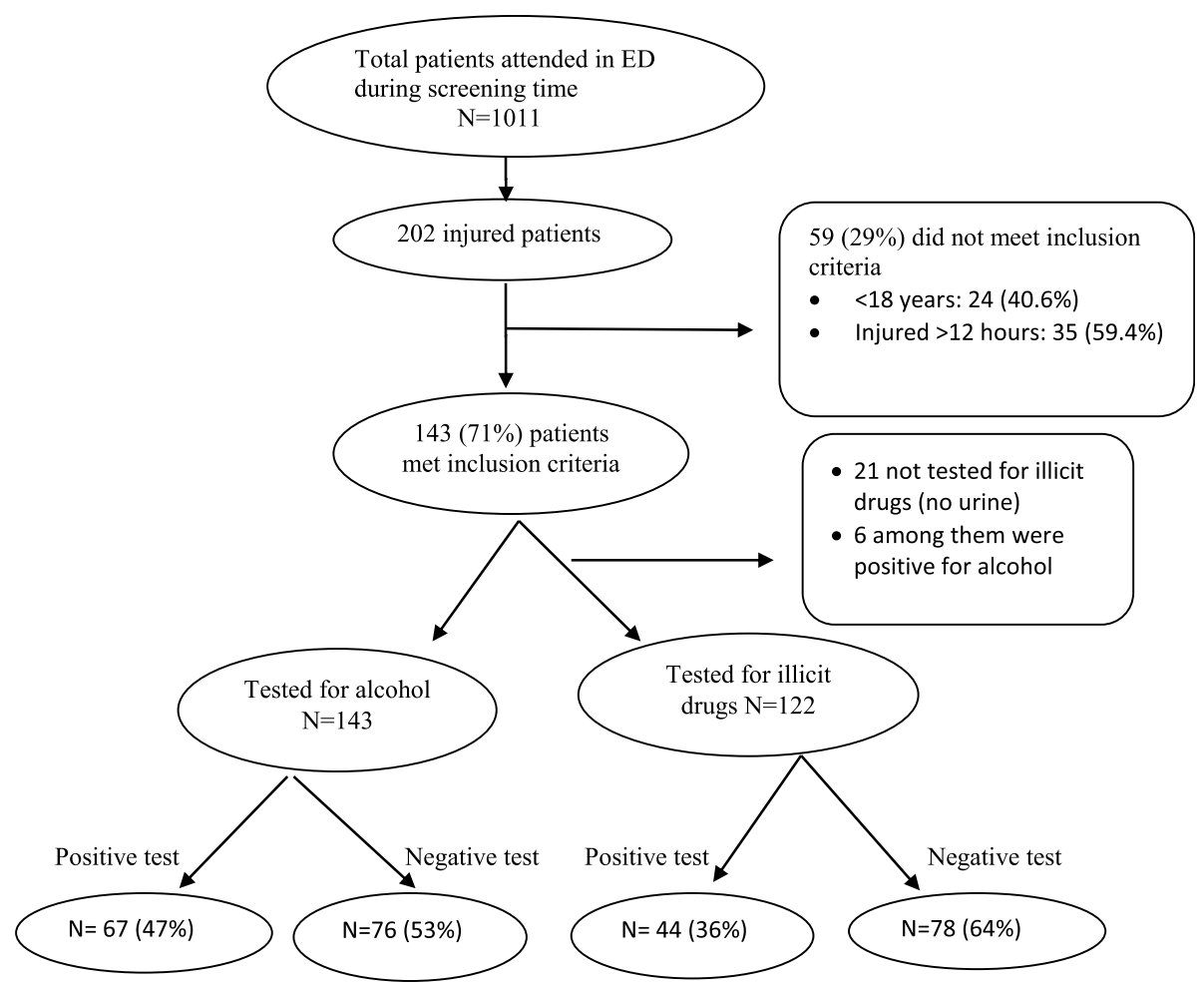

Fig. 1 Study flow chart: Inclusion criteria, Alcohol/illicit drug abuse testing 
Table 1 Study population demographics

\begin{tabular}{|c|c|c|c|}
\hline & $\begin{array}{l}\text { Total enrolled in the } \\
\text { study } N=143 n(\%)[C l]\end{array}$ & $\begin{array}{l}\text { Injured patients tested for both alcohol } \\
\text { and illicit drugs } N=122 n(\%)[\mathrm{Cl}]\end{array}$ & $\begin{array}{l}\text { Injured patients tested only } \\
\text { for alcohol } N=21 n(\%)[C I]\end{array}$ \\
\hline \multicolumn{4}{|l|}{ Gender } \\
\hline Female & 20 (14\%) [8.4-19.6\%] & 16 (13\%) [7.1-18.9\%] & $4(19 \%)$ [2.3 to $35.7 \%]$ \\
\hline Male & 123 (86\%) [80.4-91.6\%] & 106 (87\%) [81.1-92.9\%] & 17 (81\%) [64 to 97.7\%] \\
\hline \multicolumn{4}{|l|}{ Median age } \\
\hline Age Median & 30 & 30 & 33 \\
\hline$(\mathrm{QQR})$ years & $23-36$ & $23-37$ & $26-35$ \\
\hline \multicolumn{4}{|l|}{ Place of injuries } \\
\hline Road & $121(84.6 \%)$ [77.6-90.1\%] & 92 (75.4\%) [67.8-83\%] & $16(76 \%)$ [58 to 94\%] \\
\hline Home & $14(9.6 \%)$ [4.8-14.4\%] & $11(9 \%)[4-14 \%]$ & $3(14.3 \%)$ [3.0 to $36.3 \%]$ \\
\hline Work site & 6 (4\%) [0.8-7.2\%] & 5 (4\%) [1.4-7.4\%] & $1(4 . \%)$ [0.1 to $23.8 \%]$ \\
\hline Public place & $1(0.7 \%)[0.6-2 \%]$ & 0 & 0 \\
\hline Unreported & $1(0.7 \%)[0.6-2 \%]$ & 1 (0.8\%) [0.7-2.3\%] & 0 \\
\hline \multicolumn{4}{|l|}{ Referral status } \\
\hline Referred & 115 (80\%) [73.5-86\%] & 105 (86\%) [79.9\%-92.1] & 10 (47\%) [25.7-68.3\%] \\
\hline Self referral & 15 (11\%) [5.9-16.1\%] & $8(6.5 \%)$ [2.2-10\%] & 7 (33.3\%) [13.2-53.4\% \\
\hline Police & 13 (9\%) [4.4-13.6\%] & 9 (7.3\%) [2.7-11.9\%] & 4 (19\%) [2.3-35.7\%] \\
\hline
\end{tabular}

between 0.01 and $0.04 \%$; 9 (13.4\%) had blood alcohol concentrations between 0.05 and $0.09 \%$, and 16 (23.9\%) had blood alcohol concentrations greater than $0.1 \%$. Marijuana was the most common illicit drug detected and was found in $24.5 \%(n=30)$ of patients, followed by opioids $11.5 \% \quad(n=14)$, benzodiazepines $9.8 \%(n=12)$, and amphetamines $2.5 \%(n=3)$. Cocaine was not detected in any patient. Among the 122 patients tested for both alcohol and illicit drugs, 29 (23.8\%) patients tested positive for more than one substance of abuse. Of those patients, 22 (18.0\%) tested positive for two substances, 6 (4.9\%) tested positive for three substances, and 1 (0.8\%) tested positive for four substances.

Table 2 Results of alcohol and illicit drug testing among injured patients

\begin{tabular}{ll}
\hline Test & Count (\%) [Cl] \\
\hline Alcohol positive $(n=143)^{*}$ & $67(47 \%)[39.3$ to $54.7 \%]$ \\
Illicit drugs positive $(n=122)^{* *}$ & $44(36 \%)[27.2$ to $44.8 \%]$ \\
$\begin{array}{l}\text { Alcohol and illicit drugs positive } \\
(n=122)\end{array}$ & $29(24 \%)[16.5$ to $31.5 \%]$ \\
$\begin{array}{l}\text { Either alcohol or illicit drugs positive } \\
(n=143)\end{array}$ & $82(57 \%)$ [49.2 to 69.1\%] \\
$\begin{array}{l}\text { Both alcohol and illicit drugs negative } \\
(n=143)\end{array}$ & $46(32 \%)$ [24.6 to $40.5 \%]$ \\
$\begin{array}{l}\text { *This includes the patients who tested positive for alcohol alone, and those } \\
\text { who tested positive for alcohol and illicit drugs }\end{array}$ \\
**This includes the patients who tested positive for illicit drugs alone, and \\
those who tested positive for alcohol and illicit drugs
\end{tabular}

History and presumption of alcohol and illicit drugs among injured patients versus the results of analytic alcohol and illicit drug testing

Among the 143 enrolled in the study, 33 patients were not able to answer questions because of altered mental status. Among 53 patients with positive alcohol test that could answer the question, 23 (43\%) reported the use of alcohol and among the 25 patients with positive illicit drug test that could answer the question, 3 (12\%) reported illicit drug use. Among the 61 patients with positive tests for alcohol whose relatives were available for questioning, 34 (56\%) of relatives reported that the patient used alcohol prior to the injury and among the 44 patients with positive test for illicit drug use whose relatives were available, $9(82 \%)$ of the relatives reported the patient had used illicit drugs. Thus, when the patient reported that they had used alcohol, the relative risk of a positive test result was 2.4 (95\% CI: 1.7 to 3.3). However, when the patient denied alcohol use, the test was positive in 30/83 (36\%) cases. Likewise, when the patient reported that they had used illicit drugs, the relative risk of a positive test result was 3.6 (95\% CI: 1.4 to 6.0 ). However, when the patient denied illicit drug use, the test was positive in $22 / 106(21 \%)$ cases. Similarly, when a relative reported that the patient had used alcohol, the relative risk of a positive test result was 3.2 (95\% CI: 2.3 to 4.6). However, when a relative reported no alcohol use, the test was positive in 27/103 (26\%) cases. Finally, when a relative reported that the patient had used illicit drugs, the relative risk of a positive test result was 2.6 (95\% CI: 1.6 to 3.7). However, when the relative reports 
no Illicit drug use, the test was positive in 35/111 (32\%) cases (Table 3).

Among the 52 patients with positive tests for alcohol, in $43(83 \%)$ patients, the nurse presumed the patient had used alcohol. The sensitivity and specificity for the nurses' presumption of alcohol use as a predictor of the test result were $83 \%$ (95\%CI: 70 to $92 \%$ ) and $80 \%$ (95\%CI: 71 to $88 \%$ ), respectively. Among the 22 patients with positive illicit drug tests, in $1(5 \%)$ patient, the nurse presumed the patient's use of illicit drugs. The sensitivity and specificity for the nurses' presumption of illicit drug use as a predictor of the test result were 5\% (95\%CI: 0 to $23 \%$ ) and 94\% (95\%CI: 87 to $98 \%$ ), respectively. Among the 124 patients with a positive test for alcohol, physicians presumed alcohol use in 44 (85\%) patients. The sensitivity and specificity for the doctors' presumption of alcohol use as a predictor of the test result were 85\% (95\%CI: 72 to $93 \%$ ) and 80\% (95\%CI: 71 to $88 \%$ ), respectively. Among the 27 patients with positive test for illicit drug abuse, physicians presumed 2 (7\%) of the patients had used illicit drugs. The sensitivity and specificity for physician presumption of illicit drug use as a predictor of the test result were 7\% (95\%CI: 1 to $24 \%)$ and 96\% (95\%CI: 90 to 99\%), respectively.

\section{4-h and 30-days morbidity and mortality}

At $24 \mathrm{~h}$ and 30 days, the patients with positive alcohol tests were statistically more likely to have required major surgery than the patients with negative alcohol tests (RR $1.42,95 \%$ CI 1.09 to 1.85 ); the patients with positive tests for illicit drugs were also statistically more likely to get major surgery than the patients with negative tests for illicit drugs (RR: $1.59,95 \%$ CI: 1.23 to 2.06 ).
Although the results did not reach statistical significance, patients who tested positive for multiple substances were more likely to get major surgery than the patients who were positive for a single substance ingestion (RR: 1.2 ; 95\% CI: 0.73 to 1.05); patients with positive isolated alcohol test were less likely to get major surgery than the patients who tested positive for only drugs (RR: 0.93 , 95\% CI: 0.64 to 1.35 ); the patients with positive test for alcohol were more likely to have a prolonged return to baseline than those who were negative for alcohol (RR: 1.19, 95\% CI: 0.88 to 1.60 ); the patients with positive test for illicit drug were more likely to have a prolonged return to the baseline than those who tested negative for illicit drugs (RR: $1.33,95 \%$ CI: 0.97 to 1.83 ); the patients with positive tests for multiple substance ingestions were more likely to have a prolonged return to the baseline compared to those who were tested positive for one substances abuse (RR: 1.12; 95\% CI: 0.81 to 1.56 ); the patients with positive test for isolated alcohol use were more likely to have prolonged return to baseline compare to those with isolated illicit drugs use (RR: 1.1, 3, 95\% CI: 0.66 to 194); the patients who tested positive for alcohol were more likely to die than those who tested negative for alcohol (RR: 1.70, 95\% CI: 0.50 to 5.77); the patients with positive testing for illicit drugs were more likely to die than those who tested negative for illicit drugs (RR: $3.54,95 \%$ CI: 0.67 to 18.5 ); the patients who tested positive for multiple substances were more likely to die than those with single substances ingestion (RR:1.82, 95\% CI: 0.34 to 9.57); the patients with positive testing for isolated alcohol use were less

Table 3 History and presumption of alcohol/illicit drug use versus test results

\begin{tabular}{|c|c|c|c|c|c|c|c|}
\hline \multirow[b]{2}{*}{ History of use } & & \multirow[b]{2}{*}{ History of alcohol } & \multicolumn{3}{|l|}{ Alcohol test result } & \multicolumn{2}{|c|}{ Illicit drugs test result } \\
\hline & & & Positive $n=53$ & Negative $N=57$ & History of illicit drugs & Positive $n=25$ & Negative $n=89$ \\
\hline & Patients & Yes & 23 & 4 & Yes $(n=4)$ & 3 & 1 \\
\hline & & No & 30 & 53 & No $(n=106)$ & 22 & 84 \\
\hline & & History of alcohol & Positive $n=61$ & Negative $n=82$ & History of illicit drugs & Positive $n=44$ & Negative $n=78$ \\
\hline & Relatives & Yes & 34 & 6 & Yes & 9 & 2 \\
\hline & & No & 27 & 76 & No & 35 & 76 \\
\hline \multirow{9}{*}{$\begin{array}{l}\text { Presumption } \\
\text { of use }\end{array}$} & & Presumption of alcohol & Positive $n=45$ & Negative $n=98$ & Presumption of illicit drugs & Positive $n=26$ & Negative $n=98$ \\
\hline & Relatives & Yes & 10 & 38 & Yes & 8 & 4 \\
\hline & & No & 35 & 60 & No & 18 & 92 \\
\hline & & History of alcohol & Positive $n=52$ & Negative $n=91$ & History of illicit drugs & Positive $n=22$ & Negative $n=100$ \\
\hline & Nurses & Yes & 43 & 18 & Yes & 1 & 6 \\
\hline & & No & 9 & 73 & No & 21 & 94 \\
\hline & & History of alcohol & Positive $n=124$ & Negative $n=101$ & History of illicit drugs & Positive $n=27$ & Negative $n=95$ \\
\hline & Doctors & Yes & 44 & 18 & Yes & 2 & 4 \\
\hline & & No & 8 & 73 & No & 25 & 91 \\
\hline
\end{tabular}


likely to die than those who tested positive for isolated drug use (Additional file 1) (RR: 0.39, 95\% CI: 0.02 to 5.91 ) (Table 4 ).

\section{Discussion}

The demographic characteristics of our study population showed a male predominance $123(86.0 \%)$, with a median age of 30 years (23-36 years) and $85 \%$ of patients enrolled in this study were the victims of road traffic injury (RTI). This is a similar to the reported trauma burden facing many LMICs, in which, morbidity and mortality from RTIs have taken a sharp rise over the last decade due to rapid urbanization and population growth [16-19]. In this cohort, most of the victims were drivers of motorcycles, famously known as "boda-bodas", which are local motorcycle taxis used to ferry patients to different parts of the main city. This is a concerning revelation that needs urgent policy and law enforcement to protect the drivers, passengers and pedestrians.

We found that $47 \%$ of the injured patients presenting to our ED tested positive for alcohol, 36\% tested positive for the use of illicit drugs, and nearly $29 \%$ tested positive for both alcohol and illicit drugs. These are very high rates of substance abuse use compared to most of the studies we came across, including the global report on substance abuse in 2014 which reported the prevalence of alcohol and illicit drug use range respectively between 6 to $45 \%$ and 2 to $25 \%$ [14, 20-22]. In our study, alcohol was the most frequent substance found amongst injured patients (46.9\%), followed by marijuana (24.5\%), opioids (11.4\%), benzodiazepines $(9.8 \%)$ and amphetamines (2.4\%). Mariju ana was most prevalent in younger patients (median age of 26 years). Many studies on alcohol and illicit drug use conducted worldwide reported similar results as ours in terms of which substances are most frequently detected in injured patients [22-24]. The high proportion of young males using drugs and alcohol and sustaining injuries in our study is particularly concerning as this is the age group that is expected to be economically productive, and often represent the breadwinner in Tanzanian households [13, 14]. The striking number of road traffic injuries and substance use could be due to the increased availability of low-cost motorization (motorcycles), poor road infrastructure, poor enforcement of traffic laws, low rates of education, high rate of unemployment, and poor socioeconomic status in combination with relatively cheap alcohol and drugs and poor law enforcement of regulations regarding drinking and driving [12, 25-27]. This is clearly an issue that deserves additional research, and these findings begin to provide the opportunity for stratification of behavior change campaigns and public health efforts.

In this study, the results of the substances abuse screening show that $57 \%$ of the patients denied the use of alcohol and $88 \%$ denied the use of illicit drug use before the injury while the objective testing showed that they were positive. Furthermore, the presumption of patient substance abuse use by their relatives was only $12 \%$ positive for alcohol and 31\% positive for illicit drugs. The nurses and doctors' patient presumption of substances abuse use was better for alcohol than for illicit drug use. This highlights the importance of analytic testing to define this issue. Although many studies worldwide have used patient's verbal report or a questionnaire to screen for alcohol and illicit drug use in injured patients, our study and other studies, mostly conducted in $\mathrm{HIC}$, have demonstrated that analytical testing is more accurate, gives the proof of substances abuse consumption, gives information when patients are unable to, and avoids under estimation of drug and alcohol use [7-9]. One of the biggest limitations of analytic testing in our setting is the high cost of alcohol and drug testing, and this is true in most LMICs [28].

At 24-h and 30-day followup we found that injured patients who tested positive for substance abuse were more likely to require major surgery than those who tested negative. The outcomes and relative risk findings above suggest that substance abuse contributes to more severe injuries leading to surgery, and that these trauma patients had high rates of prolonged return to the normal activities, and of death. Studies conducted in sub-Saharan Africa and HICs have shown similar outcomes [29, 30]. Regulations and education on alcohol and illicit drug use, and their acute and chronic effects should be implemented or reinforced on this matter, especially in Sub-Saharan Africa.

Table 4 24-h and 30-day outcomes: relative risks of major surgery, return to the baseline, and death among injured patients testing positive for alcohol, illicit drugs, or a combination of both

\begin{tabular}{|c|c|c|c|c|c|c|}
\hline \multirow[t]{2}{*}{ Categories } & \multicolumn{2}{|c|}{ Major surgery } & \multicolumn{2}{|c|}{ Not returned to baseline } & \multicolumn{2}{|c|}{ Death } \\
\hline & $\mathrm{RR}$ & $95 \% \mathrm{Cl}$ & $\mathrm{RR}$ & $95 \% \mathrm{Cl}$ & $\mathrm{RR}$ & $95 \% \mathrm{Cl}$ \\
\hline Positive for alcohol vs negative for alcohol & 1.42 & 1.09 to 1.85 & 1.19 & 0.88 to 1.60 & 1.70 & 0.50 to 5.77 \\
\hline Positive for illicit drugs vs negative for illicit drugs & 1.59 & 1.23 to 2.06 & 1.33 & 0.97 to 1.83 & 3.54 & 0.67 to 18.5 \\
\hline $\begin{array}{l}\text { Positive for multiple substances ingestion vs single } \\
\text { substance ingestion }\end{array}$ & 0.87 & 0.73 to 1.05 & 1.12 & 0.81 to 1.56 & 1.82 & 0.34 to 9.57 \\
\hline Positive for isolated alcohol vs isolated drug use & 0.93 & 0.64 to 1.35 & 1.13 & 0.66 to 1.94 & 0.39 & 0.02 to 5.91 \\
\hline
\end{tabular}


Limitations of this study include that it was conducted at ED-MNH, a tertiary care facility and national hospital. Therefore, the results might not be generalizable to other facilities in Tanzania. We tested illicit drugs using a multi drug panel test which could only give the results of five drugs. We may have missed additional illicit drugs that were not included in our drug screen. Finally, we did not measure injury severity directly, but instead used the need for surgical intervention, return to baseline, and death as proxy measures for injury severity.

\section{Conclusion}

The prevalence of alcohol and illicit drug use is very high in patients presenting to the ED-MNH with injury. Most of the patients were young males and the majority of patients who had used drugs or alcohol prior to their injury had not returned to baseline functional level at 30 days post injury. Further studies are needed to generalise the results in Tanzania. Public health initiatives to decrease drinking and driving should be implemented.

\section{Additional file}

Additional file 1: Table S1. Relative risks of major surgery return to the baseline, and death among injured patients tested positive for alcohol/ illicit drugs (DOC $267 \mathrm{~kb}$ )

\section{Abbreviations}

\%ED: Emergency Department; 95\% Cl: 95\% confidence interval; HIC: Highincome countries; IQR: Interquartile Range; LMIC: Low- and Middle-Income Countries; MNH: Muhimbili National Hospital; RR: Relative risk; RTI: Road traffic injuries; WHO: World Health Organization

\section{Acknowledgements}

Thank you to Stacy Salerno, David Petit, Bradley Gray, Cindy Murray, Christian Salmon, Dr. Rose Mpembeni, and Dr. Said Kilindimo fort their edits during the study proposal and data analysis.

Thank you to Dr. Margaret Salmon and the Emergency Medicine Association of Tanzania (EMAT) for helping to obtain the alcohol and drug tests necessary for this research.

Thank you to Said Saleh, the research assistant for his hard work during the data collection and follow-up.

\section{Funding}

This research was not funded. The principal investigator used his personal time and funds to facilitate data collection. Test kits for alcohol and illicit drugs were donated to the project by the Emergency Medicine Association of Tanzania, Dr. Brittany Murray and Dr. Margaret Salmon, none of whom have any relationship to the makers of the testing devices/supplies. Other authors donated their time towards the project, without any funding.

\section{Availability of data and materials}

The dataset supporting the conclusions of this article is available from the authors on request.

\section{Authors contributions}

MMM contributed to the conception and design of the study, data acquisition, analyzed and interpreted the data, and drafted and wrote the manuscript. HRS contributed to the conception and design of the study, to data acquisition, analysis and interpretation of the data, and also revised the manuscript. MR critically revised the design of the study and manuscript. VM assisted in the initial design of the study and critically revised the study proposal and the manuscript. JM assisted in the initial design of the study and critically revised the manuscript. BM contributed to the conception of the study, assisted in the initial design of the study, analysis and interpretation of the data and critically revised the manuscript. All authors read and approved the final manuscript.

\section{Ethics approval and consent to participate}

The study protocol was reviewed and approved by the Senate Research and Publication Committee of Muhimbili University of Health and Allied Sciences (MUHAS) and permission to conduct the study was obtained from $\mathrm{MNH}$. All patients who met the inclusion criteria provided written informed consent.

\section{Consent for publication}

Not applicable.

\section{Competing interests}

All the authors declare that they have no competing interests.

\section{Publisher's Note}

Springer Nature remains neutral with regard to jurisdictional claims in published maps and institutional affiliations.

\section{Author details}

${ }^{1}$ Department of Emergency Medicine, Muhimbili University of Health and Allied Sciences, Dar es Salaam, Tanzania. ${ }^{2}$ Heal Africa Hospital, Goma, Democratic Republic of Congo. ${ }^{3}$ Department of Emergency Medicine, Muhimbili National Hospital, Dar es Salaam, Tanzania. ${ }^{4}$ Department of Emergency Medicine, Carolinas Medical Center, Charlotte, NC, USA. ${ }^{5}$ Division of Pediatric \Emergency Medicine, Emory University School of Medicine/ Children's Healthcare of Atlanta, Atlanta, GA, USA.

Received: 19 December 2017 Accepted: 4 January 2019

Published online: 24 January 2019

\section{References}

1. Cherpitel CJ. Focus on: the burden of alcohol use--trauma and emergency outcomes. Alcohol Res Curr Rev. 2013;35(2):150-4

2. Hofman K, Primack A, Keusch G, Hrynkow S. Addressing the growing burden of trauma and injury in low- and middle-income countries. Am J Public Health. 2005 Jan;95(1):13-7.

3. World Health Organization, International Society of Surgery. International Association of Trauma Surgery and Intensive Care, editors. Guidelines for trauma quality improvement programmes. Geneva, Switzerland: World Health Organization; 2009. p. 104

4. Derakhshanfar $\mathrm{H}$, Kalantari Meibodi M, Kariman H, Arhamidolatabadi A, Safari S. Substance abuse among drivers of motor vehicle collisions. Trauma Mon. 2012 Apr 4;17(1):236-8.

5. Gómez-Talegón T, Fierro I, González-Luque JC, Colás M, López-Rivadulla M Javier Álvarez F. Prevalence of psychoactive substances, alcohol, illicit drugs, and medicines, in Spanish drivers: a roadside study. Forensic Sci Int. 2012 Nov 30;223(1-3):106-13.

6. Legrand S-A, Houwing S, Hagenzieker M, Verstraete AG. Prevalence of alcohol and other psychoactive substances in injured drivers: comparison between Belgium and the Netherlands. Forensic Sci Int. 2012 Jul 10;220(1-3):224-31.

7. Helander A, Eriksson CIP. WHO/ISBRA study on state and trait markers ofAlcohol use and dependence investigators. Laboratory tests for acute alcohol consumption: results of the WHO/ISBRA study on state and trait markers of alcohol use and dependence. Alcohol Clin Exp Res. 2002 Jul;26(7):1070-7.

8. World Health Organization. Alcohol and injuries. In: Cherpitel CJ, editor. Emergency department studies in an international perspective. Geneva: World Health Organization; 2009. p. 286.

9. Ramchand R, Marshall GN, Schell TL, Jaycox LH, Hambarsoomians K, Shetty $\checkmark$, et al. Alcohol abuse and illegal drug use among Los Angeles County trauma patients: prevalence and evaluation of single item screener. J trauma Inj infect Crit Care. 2009 May;66(5):1461-7.

10. Bhalla K, Naghavi M, Shahraz S, Bartels D, Murray CL. Building national estimates of the burden of road traffic injuries in developing countries from all available data sources: Iran. Inj Prev J Int Soc Child Adolesc Inj Prev. 2009 Jun;15(3):150-6.

11. Mock CN, Abantanga F, Cummings P, Koepsell TD. Incidence and outcome of injury in Ghana: a community-based survey. Bull World Health Organ. 1999;77(12):955-64. 
12. Peltzer K, Ramlagan S, Johnson BD, Phaswana-Mafuya N. Illicit drug use and treatment in South Africa: a review. Subst Use Misuse. 2010 Jul;45(13):2221-43.

13. Hauli KA, Ndetei DM, Jande MB, Kabangila R. The prevalence of substance use among psychiatric patients: the case study of Bugando medical Centre, Mwanza (northern Tanzania). Subst Abuse Off Publ Assoc Med Educ Res Subst Abuse. 2011 Oct;32(4):238-41.

14. Mbatia J, Jenkins R, Singleton N, White B. Prevalence of alcohol consumption and hazardous drinking, tobacco and drug use in urban Tanzania, and their associated risk factors. Int J Environ Res Public Health. 2009 Jul;6(7):1991-2006.

15. Muhimbili Emergency Medicine Program [Internet]. [cited 2015 Jan 16]. Available from: https://emd.muhas.ac.tz.

16. Lasebikan VO, Adebayo S. Need for screening for alcohol and drugs in emergency trauma units. East Afr Med J. 2013 May;90(5):164-70.

17. Kool B, Raj N, Wainiqolo I, Kafoa B, McCaig E, Ameratunga S. Hospitalised and fatal head injuries in Viti Levu, Fiji: findings from an island-wide trauma registry (TRIP 4). Neuroepidemiology. 2012;38(3):179-85.

18. Herman J, Ameratunga S, Jackson R. Burden of road traffic injuries and related risk factors in low and middle-income Pacific Island countries and territories: a systematic review of the scientific literature (TRIP 5). BMC Public Health. 2012; 12(1):479.

19. Bener A, Rahman YSA, Mitra B. Incidence and severity of head and neck injuries in victims of road traffic crashes: in an economically developed country. Int Emerg Nurs. 2009 Jan;17(1):52-9.

20. WHO | Global status report on violence prevention 2014 [Internet]. WHO [cited 2015 Feb 19]. Available from: http://www.who.int/violence_injury_ prevention/violence/status report/2014/en/.

21. Whiteford HA, Degenhardt L, Rehm J, Baxter AJ, Ferrari AJ, Erskine HE, et al. Global burden of disease attributable to mental and substance use disorders: findings from the global burden of disease study 2010. Lancet. 2013 Nov 9;382(9904):1575-86.

22. Bakke E, Bogstrand ST, Normann PT, Ekeberg $\varnothing$, Bachs L. Influence of alcohol and other substances of abuse at the time of injury among patients in a Norwegian emergency department. BMC Emerg Med [Internet]. 2016 Dec [cited 2016 Jul 4];16(1). Available from: http://bmcemergmed. biomedcentral.com/articles/10.1186/s12873-016-0085-2

23. Cohen $\mathrm{A}$. The most frequent addictions in psychotic patients. Soins Psychiatr. 2014;8(293):8.

24. Legrand S-A, Silverans P, de Paepe P, Buylaert W, Verstraete AG. Presence of psychoactive substances in injured Belgian drivers. Traffic Inj Prev. $2013 \mathrm{Jul}$ 4;14(5):461-8.

25. Lo TQ, Oeltmann JE, Odhiambo FO, Beynon C, Pevzner E, Cain KP, et al. Alcohol use, drunkenness and tobacco smoking in rural western Kenya. Tropical Med Int Health. 2013 Apr;18(4):506-15.

26. Christophersen AS, Gjerde H. Prevalence of alcohol and drugs among car and van drivers killed in road accidents in Norway: an overview from 2001 to 2010. Traffic Inj Prev. 2014;15(6):523-31.

27. Vitale $S$, van de Mheen D. Illicit drug use and injuries: a review of emergency room studies. Drug Alcohol Depend. 2006 Mar;82(1):1-9.

28. Francis JM, Grosskurth H, Changalucha J, Kapiga SH, Weiss HA. Systematic review and meta-analysis: prevalence of alcohol use among young people in eastern Africa. Tropical Med Int Health. 2014 Apr;19(4):476-88.

29. Bava S, Jacobus J, Mahmood O, Yang TT, Tapert SF. Neurocognitive correlates of white matter quality in adolescent substance users. Brain Cogn. 2010 Apr;72(3):347-54.

30. Odgers CL, Caspi A, Nagin DS, Piquero AR, Slutske WS, Milne BJ, et al. Is it important to prevent early exposure to drugs and alcohol among adolescents? Psychol Sci. 2008 Oct;19(10):1037-44.

Ready to submit your research? Choose BMC and benefit from:

- fast, convenient online submission

- thorough peer review by experienced researchers in your field

- rapid publication on acceptance

- support for research data, including large and complex data types

- gold Open Access which fosters wider collaboration and increased citations

- maximum visibility for your research: over $100 \mathrm{M}$ website views per year

At $\mathrm{BMC}$, research is always in progress.

Learn more biomedcentral.com/submissions 